\title{
Darwin's papers
}

The Collected Papers of Charles Darwin. (2 Volumes.) Edited by Paul H. Barrett, with a Foreword by Theodosius Dobzhansky. Pp. viii $+277+326$. (University of Chicago: Chicago and London, 1977.) £27.30; $\$ 40$ the set.

These volumes bring together 152 papers which Darwin published over a period of forty-seven years. They range in length from a paragraph to forty-eight pages. Thirty-three of them first appeared in Nature, between 1869 and 1882 . Others were contributions to learned societies of which Darwin was a member: the Geological (12), Linnean (9), Zoological (4), Geographical (1), and the Royal (1). (His sole contribution to the Royal Society was his solution of the problem of the 'Parallel Roads of Glen Roy', a paper he later called a 'gigantic blunder'.)

The largest number of items (50) are from The Gardeners' Chronicle and Agricultural Gazette, the medium Darwin used for communication with plant and animal breeders. The rest of the papers are mainly from periodicals concerned with popular but serious discussion of scientific matters, like the Natural History Review.

An appendix lists fifty-two articles dealing with the species collected by Darwin on the Beagle voyage, in itself a considerable bibliographical contribution. All of Darwin's notes are preserved. Professor Barrett's notes are relatively few in number and are concerned with identifying persons and places and explaining technical terms.

The effect produced by the papers in their totality is dramatic in the way they make clear the range of Darwin's interests, his powers of observation, his imaginative questioning, his probing for facts that he hoped would corroborate his hypotheses, and his astonishing talent for experimentation.

The papers naturally vary considerably in scientific and historical significance. Some are famous. like the joint paper with Wallace in which Natural Selection was first announced, and his remarkable papers on plant physiology.

Some of the brief and apparently ephemeral items are now seen to be important in Darwin's work on his species theory. As Theodosius Dobzhansky points out in his appreciative and graceful Foreword, Darwin's short query about 'A Mouse-Coloured Breed of Ponies' was really asking 'Have the species horse and ass descended from a common ancestor'?. Similarly, Darwin's experiments on the ability of seeds to survive immersion in salt water were designed to provide him with an explanation of the geographical distribution of species that could dispense with creationism and Forbes's vast continental extensions.

Although this is primarily a reference work, there is plenty of interesting and readable material in it. Darwin wrote many of the pieces in clear nontechnical prose for those interested in such subjects as erratic boulders, the fine dust that falls on ships in the Atlantic, mimetic butterflies, the fertilisation of British orchids, the origin of certain instincts, or the biographical sketch of an infant.

Scholars will want to know how complete the collection is. The answer depends on what criteria are used in selection. Professor Barrett includes only papers published by Darwin in his lifetime. Richard Freeman, in his new edition of the bibliographical handlist of Darwin's works includes posthumous articles, memorials, and items privately printed and circulated by Darwin. On

\section{Frederick Burkhardt}

Professor Barrett's criteria, each work has four items overlooked by the other. Using $\mathrm{Mr}$ Freeman's standards, but omitting repetitive printings, nine more might have been included. For example, Darwin's important 'Queries about the Breeding of Animals' is omitted by Barrett because it was printed and distributed privately, but the 'Queries about Expression' is included because it found its way into an Annual Report of the Smithonian Institution. Again, Professor Barrett omits three items because the books to which they were contributed were published after Darwin's death. Since these circumstances in no way affect the authenticity of the writings or their importance, it seems arbitrary to deny them a place in a Collected Papers.

This editorial question aside, Professor Barrett deserves great credit for making these writings available in a convenient and reliable collection in which scholars and non-specialists alike will find both profit and pleasure.

Frederick Burkhardt, President Emeritus of the American Council of Learned Societies, is co-editor, with Sydney Smith, of the prospective Collected Letters of Charles Darwin.

\section{Complex systems}

The Foundations of Cybernetics. By F. H. George. Pp. xiv +286 . (Gordon and Breach: London, Paris and New York, 1977.) £13.50.

THE last page of this book contains the following comment ". . . about the word Cybernetics. In America it is now slightly frowned upon, and although the word is currently more acceptable in the United Kingdom it is still suspect in some quarters. .. The problem stems from the arbitrary divisions we have in our sciences, and the very slow conservative attitude of scientists towards the development of scientific ideas and classifications ....".

Up to a point the complaint deserves sympathy. Much can be gained from interdisciplinary work. There is, of course, little to stop the individual from drawing his own "arbitrary divisions". Whether his new subject becomes acceptable to the larger community depends on what it has to offer and the following it can attract.
Broadly, Cybernetics encompasses the study of complex systems. On the one hand there are the man-made systems of automation and computer technology and, on the other, those provided by nature, such as the brain of man and other physiological organs. There is, one hopes, a conceptual framework common to both. The manmade systems can serve as a source of analogies for the development of theory in psychology and physiology while, in the reverse direction, the living world can act as a source of inspiration to inventors.

The book is concerned with the, as yet undeveloped and unconnected, conceptual framework that may serve the two sides. There are chapters on feedback, finite automata, neural nets, logic, computers, information theory, and aspects of psychology and physiology. With a net cast so wide, it is not surprising to find that the treatment of some topics is superficial. This means that for information on any one 